\title{
MIKROHABITAT KATAK TANPA PARU-PARU (Barbourula kalimantanensis Iskandar, 1978) DI KAWASAN TAMAN NASIONAL BUKIT BAKA BUKIT RAYA KABUPATEN MELAWI KALIMANTAN BARAT
}

\author{
(Microhabitat of Lungless Frog (Barbourula Kalimantanensis Iskandar, 1978) In Bukit Baka \\ Bukit Raya National Park Melawi Regency West Kalimantan)
}

\author{
Sitti Maisyara, Hari Prayogo, Amir Hamidy \\ Fakultas Kehutanan Universitas Tanjungpura, Jalan Imam Bonjol Pontianak, 78124 \\ Email : Sittimaisyara@gmail.com
}

\begin{abstract}
Barbourula kalimantanensis is the only frog in Indonesian that has no lungs and only founded in Kalimantan. This study aims to study microhabitat of the lungless frog at Resot Belaban in Bukit Baka Bukit Raya National Park. The method of data collection was done by using Visual Encounter Survey (VES) combining with of tracking systems. The data are taken in 4 observations stations: Ella river 0, Ella river 1, Ella river 2, and Belaban river with tree time repeatly in each station. Based on the result, B.kalimantanensis was found only one specimen in Ella river. The microhabitat of Barbourula kalimantanensis consisted of range air temperature $25^{\circ} \mathrm{C}-30^{\circ} \mathrm{C}$, humidity $73 \%-95 \%$, water temperature at night ranges from $13^{\circ}-14^{\circ} \mathrm{C}$ and in the noon $16^{\circ} \mathrm{C}$ with a water $\mathrm{pH}$ approaching 6.50. The intensity of light entering a location with a large enough amount $125.4 \mathrm{Cd}$. Dissolved oxygen 7.10 with dissolved solids 7.53 and nondissolved solids 9. Analysis of water from the four rivers shows that the water in Ella river 0 and Belaban river have $\mathrm{pH}$ of water is close to netral $\mathrm{pH}(7)$, normal water temperature $\left(27^{\circ} \mathrm{C}\right)$, and the content of dissolved solids and undissolved solids in it. These indicate that the water from both rivers is suitable for humn consumption. The small fish and insect larvae who lived in the river are become a potential prey for B. kalimantanensis.
\end{abstract}

Keywords : Herpetofauna, Frog, Barbourula kalimantanensis, Microhabitat, TNBBBR

\section{PENDAHULUAN}

Herpetofauna merupakan salah satu potensi keanekaragaman hayati hewani yang masyarakat luas masih belum menyadari keberadaaanya. Penelitian tentang keanekaragaman dan kelimpahan herpetofauna memiliki peranan penting dalam studi biologi terutama kajian taksonomi dan ekologi. Penelitian tersebut akan bermuara pada keselarasan antara manusia dengan ekosistemnya dan lingkungan di sekitar kita yang merupakan habitat bagi makhluk hidup lainnya (Das, 1997). Herpetofauna terdiri dari dua kelas yaitu amfibi dan reptil. Amfibi memiliki 4 ordo di dunia salah satunya ordo Anura (katak dan kodok).

Katak memiliki nilai penting bagi ekosistem dan karena habitat mereka yang spesifik sementara populasi katak memiliki ancaman yang lebih besar dibandingkan jenis satwa lain sehingga dapat dijadikan sebagai indikator lingkungan yang baik atau barometer kesehatan lingkungan. Jika sesuatu terjadi pada habitatnya, mereka tidak bisa berpindah tempat seperti makhluk besar lainnya, mempelajari katak dapat 
mengetahui tentang dampak perubahan iklim mikro.

Barbourula kalimantanensis merupakan katak tanpa paru-paru endemik Kalimantan. Jenis ini tidak dilindungi menurut Peraturan Mentri lingkungan Hidup dan Kehutanan Repubik Indonesia nomor P.106/MENHK/SETJEN/KUM.1/12/20

18, tidak termasuk kedalam daftar CITES (Convention on International Trade in Endangered Species of Wild Fauna and Fora) dan didalam daftar IUCN (Inernational Union for Conservation of Nature and Natural Resources) masuk kedalam kategori genting (Endangered). Saat ini keberadaan B. kalimantanensis sulit ditemukan karena terjadi banyak perubahan alam sehingga mengganggu habitat katak tersebut. Katak ini sepanjang hidupnya berada di sungai yang bersih, berbatu dan beraliran deras sehingga mempelajari habitat katak ini juga dapat mengetahui kualitas air yang ada di kawasan Taman Nasional Bukit Baka Bukit Raya. Tujuan penelitian ini yaitu mengumpulkan data dan menganalisis mikrohabitat $B$. kalimantanensis.

\section{METODE PENELITIAN}

Penelitian dilaksanakan pada 26 November - 26 Desember 2018 Di Kawasan Taman Nasional Bukit Baka Bukit Raya Kabupaten Melawi, Kalimantan Barat. Alat dan bahan yang digunakan dalam penelitian ini adalah GPS (Global Positioning System), meteran, headlamp/senter, kaca selam, kamera, higrometer, termometer, $\mathrm{pH}$ meter dan lux meter.

Metode pengumpulan data menggunakan metode survei perjumpaan visual / VES (Visual Encounter Survey) artinya jenis yang kelihatan diamati dan dicatat (Heyer et al., 1994) dan pengambilan jalur pengamatan menggunakan metode jalur/transek. Peletakan jalur berdasarkan tipe habitat aquatik karena katak ini menghabiskan sepanjang hidupnya didalam air. Lokasi pengamatan berada di empat stasiun pengamatan yaitu: Sungai Ella 0, Sungai Ella 1, Sungai Ella 2 dan Sungai Belaban. Jalur pengamatan pada induk sungai 300 meter dan anak sungai 200 meter dengan lebar jalur mengikuti lebar sungai. Pada jalur pengamatan setiap 150 meter pada sungai utama dan 100 meter pada anak sungai akan dilakukan penandaan, hal tersebut dilakukan agar mempermudah penentuan titik tempat ditemukannya katak tersebut dan untuk mempermudah pengambilan data mikrohabitat. Kemudian dilakukan tiga kali pengulangan pada stasiun pengamatan. Pengamatan dilakukan pada siang hari pukul 10.00 - 14.00 WIB dan malam hari pukul $19.00-21.00$ WIB.

Peta lokasi penelitian : 
JURNAL HUTAN LESTARI (2019)

Vol. 7 (2) : $753-762$

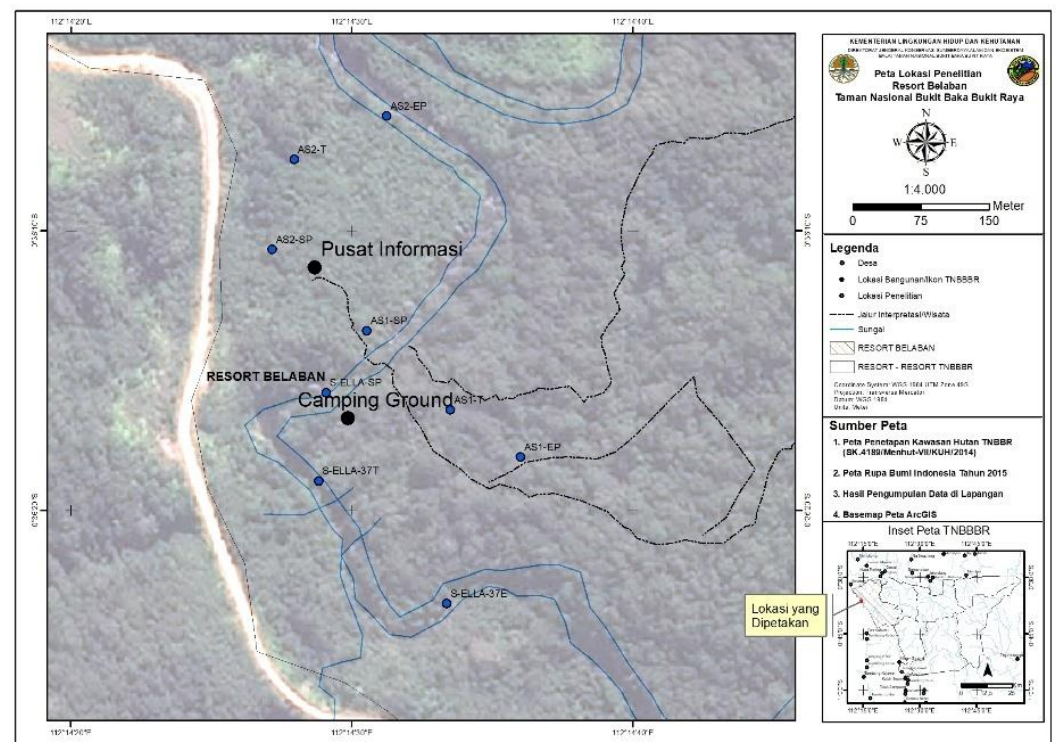

Gambar 1. S.Ella : Sungai Ella 0 (Stasiun pengamatan 1), AS1 : Sungai Ella 1 (Stasiun pengamatan 2), AS2 : Sungai Ella 2 (Stasiun pengamatan 3) S.Ella : Ella River 0 (Observation station 1), AS1 : Ella River 1 (Observation station 1), AS2 : Ella River 2 (Observation station 2)

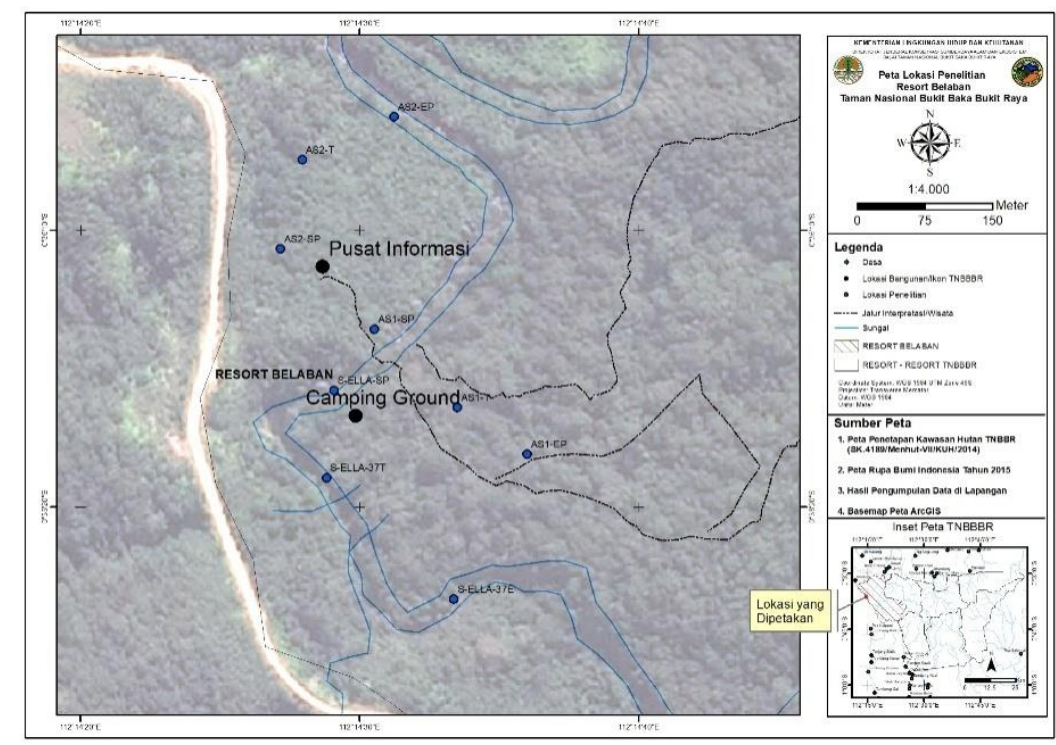

Gambar 2. SBL : Sungai Belaban (Stasiun pengamatan 4) Belaban River (Observation station 4)

\section{Analisis Data}

Data yang dianalisis ada tiga, yaitu data mikrohabitat dengan mengukur parameter lingkungan: suhu udara dan air, kelembaban udara, $\mathrm{pH}$ air, turbidity meter, substrat, naungan, padatan terlarut (Total Disolved Solids), padatan tidak terlarut (Total Suspended Solids) dan kandungan oksigen (Dissloved Oxygen). Analisis yang kedua yaitu vegetasi sempadan sungai secara kualitatif dengan melihat vegetasi 
dominan yang tumbuh disekitar sungai dan kerapatannya. Analisis yang ketiga yaitu analisis ancaman gangguan dan perubahan baik di habitat maupun disekitar habitat $B$. kalimantanensis seperti adanya pertambangan dan pembalakan liar.

\section{HASIL DAN PEMBAHASAN}

Hasil penelitian yang telah dilakukan ditemukan satu individu $B$. kalimantanensis yaitu pada stasiun pertama yaitu di stasiun pengamatan Sungai Ella 0 tepatnya di Km 37.

A
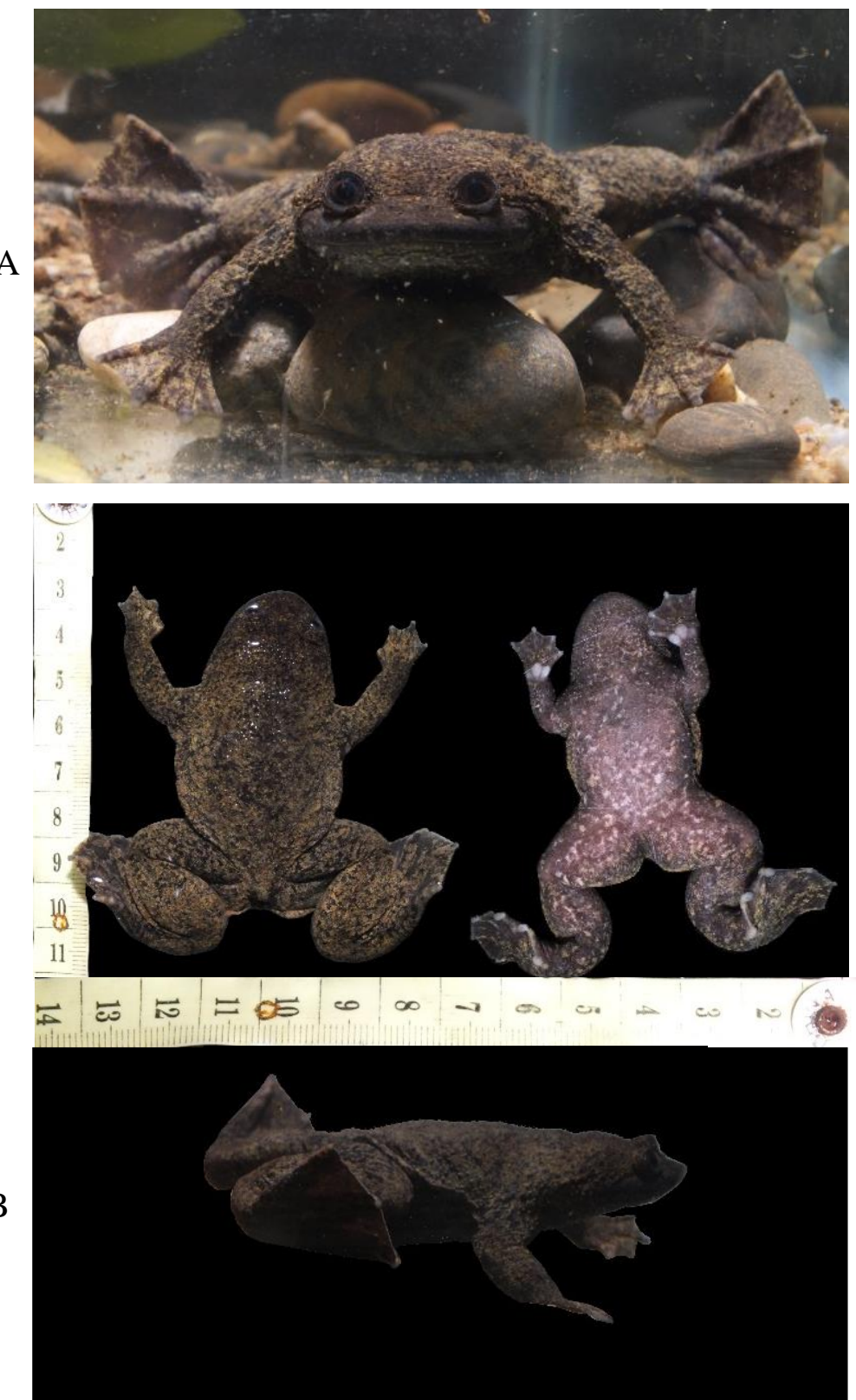

Gambar 3. Spesimen segar Barbourula kalimantanensis MZB Amph 31970 (A), tampak dorsal, ventral dan lateral (B) (Fresh specimens of Barbourula kalimantanensis MZB Amph 31970 (A), dorsal look, ventral and lateral (B)) 
B. kalimantanensis secara morfologi menunjukkan spesialisasi ekstrim untuk perairan hidup di habitat tertentu yang mengurangi kemampuannya untuk hidup di tempat lain (Bickford et al. 2008). B. kalimantanensis tidak satu pun ditemukan di antara batu dengan daun mati atau jenis puing-puing lainnya, mungkin menghindari air dengan kandungan oksigen lebih sedikit yang disebabkan oleh bahan pembusukan (Rachmayuningtyas, 2011). Hal ini juga terjadi pada saat penelitian ini dilakukan bahwa tidak ditemukannya $B$. kalimantanensis pada dua stasiun pengamatan yang airnya sudah kotor karena sampah daun dan kayu mati.

Tanpa paru-paru adalah adaptasi khusus untuk hidup di habitat tertentu, secara efektif mencegah spesies yang hidup di tempat lain. Evolusi dan ekologi tanpa paru-paru adalah fisiologis yang kompleks melibatkan banyak mekanisme yang berbeda. Pada B. kalimantanensis keseimbangan evolusi dan ekologi menyebabkan hilangnya paru-paru sebagai penyebab utama permukaan pernapasan untuk pertukaran gas $B$. kalimantanensis terjadi dalam suhu air yang dingin (14$17{ }^{\circ} \mathrm{C}$ ) kecepatan arus air $2-5 \mathrm{~m} / \mathrm{s}$ (Rachmayuningtyas, 2011). Pada Agustus 2007 di sekitaran Daerah
Nanga Pinoh, ditemukan bahwa penambangan emas ilegal telah menghancurkan semua habitat yang cocok untuk B. Kalimantanensis. Kualitas air di sekitar tipe lokalitas tidak lagi cocok untuk jenis ini, tetapi kemudian didapatkan dua individu baru B. kalimantanensis di hulu sungai (Bickford et al. 2008). Pada penelitian ini suhu air $15-16^{\circ} \mathrm{C}$ pada siang hari dan $13-16^{\circ} \mathrm{C}$ malam hari serta kecepatan arus air 1-2 m/s. Pada penelitian sebelumnya dan penelitian yang telah dilakukan saat ini terdapat suhu yang berbeda karena penelitian dilakukan pada bulan yang berbeda yaitu pada bulan Agustus (kemarau) dan bulan Desember (hujan) serta kecepatan arus air berbeda. Lokasi tempat ditemukannya $B$. kalimantanensis merupakan hulu sungai di Daerah Nanga Pinoh sama dengan jejak rekam penemuan diatas namun memiliki titik koordinat yang berbeda. Titik koordinat ditemukannya $B$. kalimantanensis pada stasiun pengamatan 1 Sungai Ella 0 yaitu $112^{\circ} 14 ' 28,756^{\prime \prime}$ E - 0³6'18,940" S.

Berikut adalah data hasil pengamatan langsung di lapangan dan hasil uji laboratorium data lokasi tempat B.kalimantanensis ditemukan pada stasiun pertama yaitu di stasiun pengamatan Sungai Ella 0 : 
Tabel 1. Data parameter lingkungan ditemukannya Barbourula kalimantanensis (Environmental parameters data found in Barbourula kalimantanensis)

\begin{tabular}{|c|c|}
\hline \multicolumn{2}{|c|}{$\begin{array}{c}\text { Katak Tanpa Paru-Paru } \\
\text { (Barbourula kalimantanensis Iskandar, 1978) }\end{array}$} \\
\hline Suhu Udara Siang & $27^{\circ} \mathrm{C}$ \\
\hline Suhu Udara Malam & $25^{\circ} \mathrm{C}$ \\
\hline Kelembaban Udara Siang & $63 \%$ \\
\hline Kelembaban Udara Malam & $64 \%$ \\
\hline Suhu Air Siang & $16^{\circ} \mathrm{C}$ \\
\hline Suhu Air Malam & $14{ }^{\circ} \mathrm{C}$ \\
\hline pH Siang & 5,98 \\
\hline pH Malam & 6,12 \\
\hline Kecepatan Arus Air & 100 meter / 60 detik \\
\hline Turbidity Meter & $62 \mathrm{~cm}$ dari permukaan air \\
\hline Intensitas Cahaya & 125,5 Candela $(\mathrm{Cd})$ \\
\hline TDS (Total Disolved Solids) & $3,6 \mathrm{Mg} / \mathrm{L}$ \\
\hline TSS (Total Suspended Solids) & $9 \mathrm{Mg} / \mathrm{L}$ \\
\hline DO (Dissloved Oxygen) & $7,10 \mathrm{ppm}$ \\
\hline Substrat & Pasir berbatu \\
\hline Lebar Sungai & 23,30 meter \\
\hline Kedalaman Sungai & 0,35 meter $-1,65$ meter \\
\hline Keterangan $\quad:$ & \\
\hline $\begin{array}{l}\text { Turbidity meter } \\
\text { TDS (Total Disolved Solids) } \\
\text { TSS (Total Suspended Solids) } \\
\text { DO (Dissloved Oxygen) }\end{array}$ & $\begin{array}{l}\text { Kejernihan air. } \\
\text { Padatan terlarut. } \\
\text { Padatan tidak terlarut. } \\
\text { Oksigen terlarut. }\end{array}$ \\
\hline
\end{tabular}

Tabel 1 menjelaskan bahwa suhu air siang dan malam berbeda karena kondisi air juga berbeda yang disebabkan oleh pasang surut air, kelembaban siang maupun malam tidak mengalami perbedaan yang signifikan dan $\mathrm{pH}$ air mendekati $\mathrm{pH}$ normal (7). Cahaya matahari yang masuk kedalam sungai dalam jumlah yang besar yaitu $125,5 \mathrm{Cd}$, padatan terlarut dan tidak terlarut sangat sedikit sehingga kandungan oksigen terlarut didalamnya pun besar dengan tingkat kejernihan atau turbidity yang tinggi dari permukaan air. Batuan kecil dipermukaan sungai yang dangkal juga menjadi tempat naugan yang sesuai bagi B. kalimantanensis. Hasil data parameter tersebut dapat dijadikan perbandingan dengan parameter yang diambil pada stasiun pengamatan atau sungai yang berbeda. Katak ditemukan pada kedalaman 0,06 meter berada diantara celah batu dengan substrat di dasar sungai adalah pasir berbatu. Posisi katak pada saat ditemukan yaitu 12,30 meter dari kanan dan 11 meter dari kiri (ke arah hulu sungai). Faktor utama adanya katak tersebut dilokasi selain kondisi lingkungan adalah sumber 
makanan, yang menjadi sumber makanan bagi katak tersebut adalah ikan-ikan kecil di sungai salah satunya adalah dari ikan Gastromyzon sp. dan berbagai jenis ikan kecil lainnya serta larva serangga atau serangga air.

Barborula kalimantanensis hanya ditemukan pada stasiun pengamatan pertama yaitu Sungai Ella 0 sedangkan pada stasiun pengamatan dua, tiga dan empat tidak ditemukan. Sebagai spesies katak tanpa paru-paru $B$. kalimantanensis membutuhkan tingkat oksigen bebas yang sangat tinggi yang hanya ada pada sungai beraliran deras, jernih, dingin dan dangkal. Barborula kalimantanensis tidak ditemukan di antara batu-batu dengan sampah daundaun dan kayu mati untuk menghindari kandungan oksigen yang lebih sedikit akibat bahan-bahan organik yang membusuk. Oleh sebab itu di stasiun pengamatan kedua dan ketiga tidak ditemukan karena banyaknya sampah daun dan kayu mati pada aliran sungai serta tingginya permukaan air karena hujan pada stasiun pengamatan keempat. Berdasarkan hasil analisis data dari semua parameter yang diukur terjadinya perbedaan yang signifikan pada stasiun pengamatan ketiga yaitu Sungai Ella 2 karena tingginya padatan atau partikel-partikel yang tidak terlarut sehingga menyebabkan kekeruhan pada air. Air sungai ini mengeluarkan bau yang tidak sedap karena banyaknya sampah kayu dan daun busuk serta aliran sungai ini merupakan aliran dari pembuangan dari perusahaan yang ada di sekitar Taman Nasional.

Pada saat ditemukan katak ini memuntahkan sisa makannya yang belum tercerna yaitu ekor ikan dari genus Gastromyzon sp. dan serangga dari ordo Isoptera. Sisa makanan lainnya sudah hancur atau dicerna sehingga tidak teridentifikasi. Selain kondisi lingkungan sekitar, sumber makanan juga menjadi salah satu faktor adanya $B$. kalimantanensis. Bagian terpenting dari penyusun mikrohabitat selain faktor biotik juga ada faktor abiotik didalamnya yang memiliki keterkaitan, oleh karena itu dua faktor ini adalah satu kesatuan yang tidak dapat dipisahkan sebagai penyusun mikrohabitat.

\section{Analisis Mikrohabitat}

Parameter lingkungan yang menjadi penyusun mikrohabitat di ukur langsung di lapangan dan beberapa parameter lainnya seperti air di uji di laboratorium. Parameter yang diuji adalah padatan terlarut (Total Disolved Solids), padatan tidak terlarut (Total Suspended Solids) dan kandungan oksigen (Dissloved Oxygen). 
Tabel 2. Hasil rata-rata dan perbandingan parameter lingkungan (Avarage results and comparison of environmental parameters)

\begin{tabular}{|c|c|c|c|c|c|c|}
\hline \multirow{2}{*}{ No. } & \multirow{2}{*}{ Parameter } & \multicolumn{4}{|c|}{ Lokasi } & \multirow{2}{*}{ Satuan } \\
\hline & & S.Ella 0 & S.Ella 1 & S.Ella 2 & S.Belaban & \\
\hline 1. & Suhu Udara Siang & 28 & 24 & 27 & 30 & ${ }^{\circ} \mathrm{C}$ \\
\hline 2. & Suhu Udara Malam & 25,1 & 26,4 & 22,6 & 28,5 & ${ }^{\circ} \mathrm{C}$ \\
\hline 3. & Kelembaban Siang & 73,3 & 93 & 67,9 & 95 & $\%$ \\
\hline 4. & Kelembaban Malam & 74 & 53,3 & 54,6 & 95,6 & $\%$ \\
\hline 5. & Suhu Air Siang & 16 & 15,3 & 16,3 & 16 & ${ }^{\circ} \mathrm{C}$ \\
\hline 6. & Suhu Air Malam & 14 & 14,2 & 16,3 & 13,2 & ${ }^{\circ} \mathrm{C}$ \\
\hline 7. & pH Siang & 6,50 & 5,97 & 6,00 & 6,06 & \\
\hline 8. & pH Malam & 6,19 & 6,06 & 6,11 & 6,12 & \\
\hline 9. & Kecepatan Arus Air & $100 / 60$ & $100 / 413,7$ & $100 / 184,8$ & $100 / 135$ & meter/detik \\
\hline 10. & Turbidity Meter & 57 & 42 & 3 & 60 & \\
\hline 11. & Intensitas Cahaya & 125,4 & 85,3 & 115,3 & 67,2 & Candela \\
\hline 12. & $\begin{array}{l}\text { TDS (Total Disolved } \\
\text { Solids) }\end{array}$ & 7,53 & 12,5 & 9,8 & 11,8 & $\mathrm{Mg} / \mathrm{L}$ \\
\hline 13. & $\begin{array}{l}\text { TSS (Total Suspended } \\
\text { Solids) }\end{array}$ & 9 & 5 & 11 & 9 & $\mathrm{Mg} / \mathrm{L}$ \\
\hline 14. & $\begin{array}{l}\text { DO (Dissolved } \\
\text { Oxygen) }\end{array}$ & 7,10 & 6,10 & 7,10 & 7,10 & ppm \\
\hline 15. & Substrat & $\begin{array}{l}\text { Pasir } \\
\text { berbatu } \\
\text { dengan } \\
\text { sedikit } \\
\text { serasah }\end{array}$ & $\begin{array}{l}\text { Batu } \\
\text { berpasir } \\
\text { dengan } \\
\text { banyak } \\
\text { serasah }\end{array}$ & $\begin{array}{l}\text { Batu } \\
\text { berpasir } \\
\text { dan } \\
\text { banyak } \\
\text { serasah }\end{array}$ & $\begin{array}{l}\text { Pasir } \\
\text { berbatu } \\
\text { dengan } \\
\text { sedikit } \\
\text { serasah }\end{array}$ & \\
\hline
\end{tabular}

Keterangan :

S.Ella $0 \quad$ : Sungai Ella 0

S.Ella $1 \quad$ : Anak Sungai Ella 1

S.Ella 2 : Anak Sungai Ella 2

S. Belaban : Sungai Belaban

Tabel 3 dapat diketahui bahwa keempat stasiun pengamatan memiliki beberapa perbedaan yang mungkin membuat B. kalimantanensis tidak ditemukan didalamnya. Hasil pengukuran oksigen terlarut pada ke tiga lokasi sama dan satu lokasi kandungan oksigen lebih rendah. Padatan terlarut pada empat stasiun berbeda dan padatan tidak terlarut pada empat stasiun memiliki kesamaan pada stasiun pertama dan keempat sedangkan dua stasiun lainnya berbeda signifikan. Sungai Ella 1 memiliki padatan terlarut terbanyak dan Sungai Ella 0 memiliki padatan terlarut paling sedikit. Sungai Ella 2 memiliki padatan tidak terlarut paling banyak dan anak Sungai Ella 1 memiliki padatan terlarut paling sedikit. $\mathrm{pH}$ air yang paling mendekati $\mathrm{pH}$ 
normal adalah pada Sungai Ella 0 dan juga pada sungai ini intensitas cahaya yang masuk adalah yang paling besar. Berdasarkan hasil diatas dapat diketahui bahwa pada Sungai Ella 0 dan Sungai Belaban memiliki kesamaan atau parameter yang tidak jauh berbeda yang sesuai dengan kriteria mikrohabitat bagi B. kalimantanensis walaupun pada Sungai Belaban tidak ditemukan karena pada saat penelitian permukaan air sungai sedang tinggi. Pada Sungai Ella 1 dan 2 keadaan lokasi tidak jauh berbeda seperti banyaknya serasah daun dan kayu mati pada sungai yang membuat katak tersebut tidak bisa hidup didalamnya.

\section{Analisis Vegetasi Sempadan Sungai}

Hasil analisis vegetasi secara kualitatif, dapat diketahui bahwa adanya pohon di sekitaran sungai tidak mempengaruhi habitat bagi $B$. kalimantanensis ini karena naungan bagi katak ini adalah batu bukan berasal dari tanaman disekitar sungai. Pohon ini secara langsung tidak mempengaruhi debit aliran air sungai, namun secara tidak langsung kotoran dari pohon tersebut seperti daun dan kayu mati yang jatuh ke sungai mempengaruhi mikrohabitat bagi $B$. kalimantanensis karena semakin banyak daun dan kayu mati yang ada di dalam sungai dapat mempengaruhi kandungan oksigen terlarut akibat pembusukan yang terjadi.

\section{Analisis Gangguan dan Ancaman}

Hasil pengamatan dilapangan, gangguan dan ancaman yang sering terjadi di lokasi yang menjadi habitat bagi B. kalimantanensis adalah aktivitas berburu warga seperti berburu ikan. Katak ini menjadi salah satu yang ikut diambil pada saat berburu oleh masyarakat untuk dikonsumsi. Rusaknya lingkungan sekitar dan banyaknya aktivitas manusia seperti berladang dan penebangan liar di hulu dan sekitar lokasi juga dapat mengganggu katak tersebut, sifat sensitifnya terhadap perubahan lingkungan. Menjaga sungai agar tetap bersih bebas dari perburuan seperti menuba' atau memberi racun (alami maupun buatan) pada sungai untuk menangkap ikan agar kondisi sungai tetap baik dan layak di hidup oleh $B$ kalimantanensis karena sifat sensitifnya terhadap perubahan lingkungan.

\section{Kesimpulan}

Berdasarkan hasil penelitian yang telah dilakukan dapat diketahui bahwa mikrohabitat B.kalimantanensis adalah suhu udara berkisar antara $25^{\circ}-30{ }^{\circ} \mathrm{C}$, kelembaban $73 \%-95 \%$ dengan suhu air malam berkisar antara $13-14^{\circ} \mathrm{C}$, suhu air siang $16^{\circ} \mathrm{C}$ dan $\mathrm{pH}$ air mendekati normal (7) yaitu 6,50. Intensitas cahaya yang masuk kedalam lokasi dengan jumlah yang cukup besar berkisar antara 125,4 Cd. Oksigen terlarut 7,10 dengan padatan terlarut 7,53 dan padatan tidak terlarut 9. Sungai yang bersih atau mengandung sedikit daun dan kayu mati menjadi salah satu faktor yang menentukan mikrohabitat katak tersebut karena semakin sedikit sampah atau kotoran di dalam air semakin besar pula oksigen terlarut di dalamnya sedangkan jika banyak kotoran di dalam air dapat 
menyebabkan turunnya kadar oksigen akibat dari proses pembusukan kotoran tersebut. Debit air yang deras, serta tepian sungai yang dangkal dengan substrat pasir dan bebatuan yang menjadi naungan bagi katak tersebut. Ikan kecil yang hidup di dalam sungai menjadi sumber makanan bagi $B$. kalimantanensis. Menjaga kondisi sungai agar tetap baik bebas dari racun atau tuba' dan tambang emas agar air dapat di konsumsi dan dapat menjadi habitat yang baik dan layak bagi $B$. kalimantanensis maupun satwa lainnya yang hidup di dalam sungai.

\section{Saran}

Diperlukan perhatian khusus terhadap B. kalimantanensis karena terbatasnya sebaran dan kondisi populasi yang semakin berkurang di alam liar. Menjaga kualitas air sebagai habitat B. kalimantanensis agar tidak tercemar dengan sosialisasi kepada masyarakat sekitar terkait aktifitas penangkapan ikan di sekitar lokasi perjumpaan katak tersebut namun dengan memberikan opsi tempat yang lain.

\section{Ucapan Terimakasih}

Kepada pihak Balai Taman Nasional Bukit Baka Bukit Raya yang telah memberikan izin dalam penelitian ini.

\section{DAFTAR PUSTAKA}

Bickford, D. Iskandar, D., Barlian, A. 2007. A Lungless frog discovered on Borneo. Magazine Current Biology 18(9).

Das I. 1997. Conservation problem of tropical Asia's most threatened turtle, In: Van Abbema, J. (Ed). Proceeding : Conservation, restroration and management of tortoise and turtle, Kinabalu.

Heyer WR, Donnelly MA, McDiarmid RV, Hayek LA \& Foster MS.(eds). 1994. Measuring and Monitoring Biological Diversity. Standar Methods for Amphibians. Smithsonian Institution Press, Washington DC.

Rachmayuningtyas, B.A., D.P. Bickford, M. Kamsi, S.N. Kutty, R. Meier, U. Arifin, A. Rachmansah \& D.T. Iskandar (2011). Conservation status of the only Lungless Frog Barbourula kalimantanensis Iskandar, 1978 (Amphibia: Anura: Bombinatoridae). Journal of Threatened Taxa 3(8). 